ARTICLE

\title{
Elastic-Plastic Connection Model Describing Dynamic Interactions of Component Connections
}

\author{
Akemi NISHIDA ${ }^{1, *}$, Fumimasa ARAYA ${ }^{1}$, Noriyuki KUSHIDA ${ }^{1}$, Makoto KONDO ${ }^{2}$, \\ Michiya SAKAI ${ }^{3}$ and Yuzo SHIOGAMA ${ }^{3}$ \\ ${ }^{1}$ Japan Atomic Energy Agency, 6-9-3, Higashi-ueno, Taito ward, Tokyo 110-0015, Japan \\ 2 Japan Atomic Energy Agency, 4002 Narita-cho, Oarai-machi, Higashiibaraki-gun, Ibaraki 311-1393, Japan \\ ${ }^{3}$ Central Research Institute of Electric Power Industry, 1646, Abiko, Abiko city, Chiba 270-1194, Japan
}

\begin{abstract}
Design evaluation of nuclear facilities would be facilitated by a numerical evaluation system that can evaluate both global and local behaviors under severe seismic loading. A critical part of such a system is the numerical model describing the dynamic physical interactions among component connections, called the elastic-plastic connection model. Here we propose such a model and use it to simulate dynamic interactions using real earthquake and plant data from the High Temperature Engineering Test Reactor (HTTR) at the Oarai Research and Development Center of the JAEA. We focus on joints connecting the component supports and the building walls, which generally involve fixed/pinned boundary conditions. Precision was increased by adjusting model parameters to fit experimental data. The results confirmed a reduction in the vibration response and a change in the natural frequencies of individual components under large virtual earthquake loading, which are considered to have resulted from dynamic interactions between the joints connecting the component supports and the building walls.
\end{abstract}

KEYWORDS: elastic-plastic connection model, dynamic interaction, earthquake response, plant simulation

\section{Introduction}

Public concern for earthquake safety and inspection of nuclear plants is increasing in light of recent revelations that, for example, the acceleration responses of a certain nuclear plant exceeded the design values during an earthquake. This is, indeed, a cause for worry and must be quickly addressed by evaluating the earthquake resistance of extant nuclear plants and proving sufficient factor of safety in structural strength. The 2004 White Paper on Nuclear Safety commissioned by the Nuclear Safety Commission of Japan ${ }^{1)}$ states that the incidence of joint failure in plant components was comprise an equivalent of $65 \%$ of all failures. To address this, ideally, actual-scale experiments are necessary, which would allow precise determination of the properties of these joints. But the cost and time required makes this impractical. A conventional numerical simulation often requires the assumption of simple analysis conditions to reduce computational complexity when attempting to model the whole structure. ${ }^{2-4)}$ What is particularly needed is a model that can be used to determine the possibility of joint damage in mechanical and structural components under unusually large earthquake loads.

The objective of this research is to develop a numerical evaluation system that can evaluate both global and local behaviors of facilities under severe seismic loading. One important step toward realizing this objective is the development of a numerical model describing the dynamic interactions of component connections, called the elas-

*Corresponding author, E-mail: nishida.akemi@jaea.go.jp tic-plastic connection model. We focus on the joints connecting the component supports and the building walls, which generally involve fixed/pinned boundary conditions. By introducing this elastic-plastic connection model into a large-scale elastic structural model, ${ }^{5)}$ it becomes possible to analyze the gestalt structural response, including all the local elastic-plastic behaviors of structures at the connections. In this manner, it becomes possible to evaluate both global and local behaviors of the structure.

First, to understanding of the mechanical behavior of the joints and validate the proposed elastic-plastic connection model, we conducted a hybrid experiment, which involved both an actual experimental load test and numerical simulation. This allowed investigation of the real seismic performance under large deformation and/or near the point of structural collapse under strong ground motion. This technique is effective for large-scale facilities, which cannot be tested in actual size. The experimental results revealed the characteristic dynamic behavior of the joints and allowed validation of the model by comparison with calculated predictions.

Furthermore, we applied the proposed elastic-plastic connection model to modeling joints in the High Temperature Engineering Test Reactor (HTTR) of the Japan Atomic Energy Agency (JAEA) as an example of a real-world application. We identified the effectiveness of the simulation by comparing the numerical results with the earthquake response observation records of HTTR at the elastic level and also inspected the influence of the elastic-plastic behavior at the connections on gestalt behavior under large simulated 


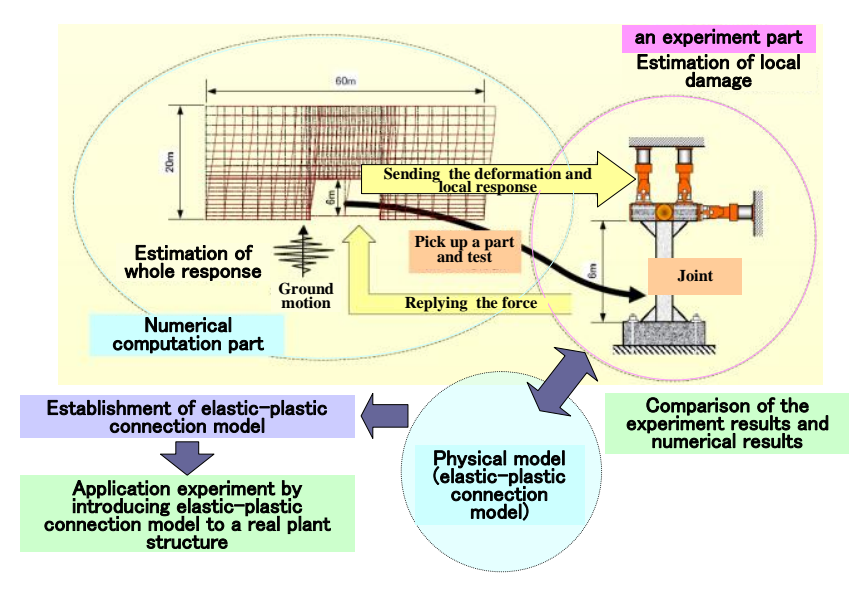

Fig. 1 Overview of the study

earthquake loads sufficient to damage some joints. The overview of the study is shown in Fig. 1.

\section{Elastic-Plastic Connection Model}

Here, the interaction between joints (including the embedded fastener) connecting component supports and the building walls (Fig. 2) was modeled using the proposed elastic-plastic connection model. The supports and the building transmit forces through the embedded fastener (Fig. 3). Note that during the conventional design process, cyclic loading is not considered for embedded fasteners. Rather, only simple vertical tension force, horizontal shear force, and combinations of the two are considered. ${ }^{6)}$ The proposed elastic-plastic connection model (Fig. 4), however, allows for the random cyclic loads seen during earthquakes. The conventional model covers a part of a beam element, ${ }^{7,8)}$ but we changed the specifications to be able to insert it over a part of a finite solid element and developed. In addition, the Ramberg-Osgood model ${ }^{9)}$ was introduced to model the elastic-plastic hysteresis and sliding at metal joints seen in the experiments (Fig. 5). Furthermore, though the conventional model was applicable to only a part of the structural member, the proposed model was developed to be applicable to both a part of the member and boundary interfaces. A benchmark test was performed by using the conventional model and the proposed model, as shown in Fig. 6. A vertical sin wave was loaded at the top of the model. The comparison between the results shows good agreement and it confirmed the validity of the assumed hysteresis model. In this way, the framework of elastic-plastic connection model was prepared.

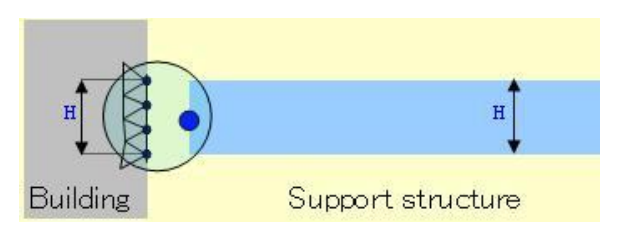

Fig. 2 Joint connecting the component supports and the building walls

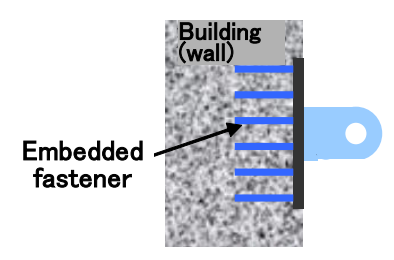

Fig. 3 Embedded fastener

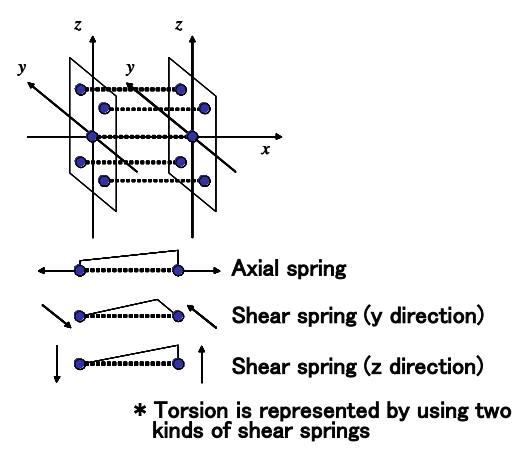

Fig. 4 Spring model of elastic-plastic connection

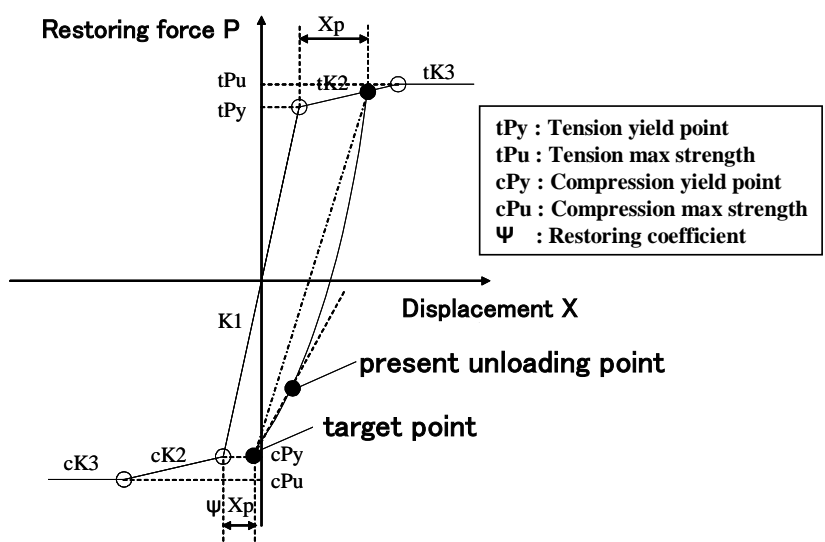

Fig. 5 Hysteresis characteristics of each spring (Ramberg-Osgood model)

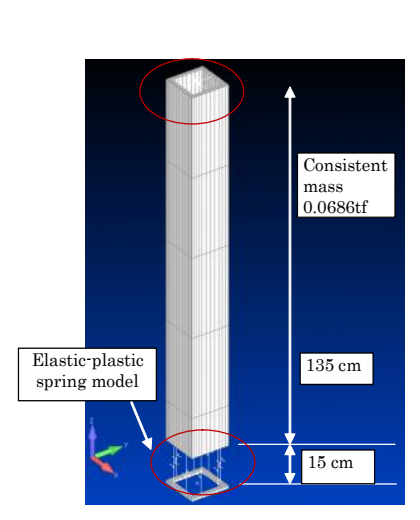

(a) Test model

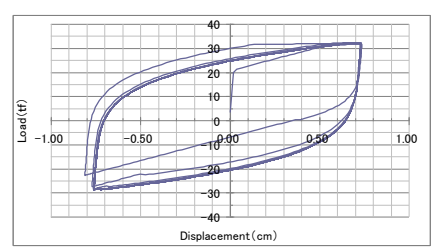

1) Conventional model (beam)

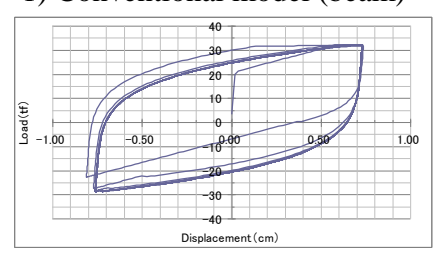

2) Proposed model (3D)

(b) Test results

(Load-displacement relation for a spring model)

Fig. 6 Benchmark test 


\section{Hybrid Experiment}

\section{Methods Summary}

When performing a loading experiment on the joints, it is critical to consider the interaction between the support structures and the building walls ${ }^{10-14)}$ and to clarify the mechanical characteristics of the joints under seismic load. However, when studying the seismic response of the piping system and heat exchanger, which are important facilities in a nuclear plant, large-scale experimental models are necessary, which entail considerable cost. Therefore, we resort to the hybrid experiment method, fusing numerical analysis and real experiment, as described in the Introduction. Briefly, actual experimental test specimens were created only for critical components, whereas the rest were simulated.

In this study, a hybrid seismic response experiment was performed for a total of five component support structures: four piping support structures and one equipment support structure. These specimen and all test cases are shown in Table 1. A photograph of the hybrid experiment setup for a piping support structure is shown in Fig. 7. Experimental models were fabricated for four kinds of framed restraints for piping support in actual size as shown in Fig. 8 and an upper support structure for the intermediate heat exchanger (IHX) of HTTR on one-third scale as shown in Fig. 9. The main vibration modes of the whole experimental system, including the specimens, were determined in reference to the design information of HTTR. A real-time hybrid experiment system linked to the loading apparatus was performed by using fast dynamic hydraulic actuators and numerical simulation of the entire system on a high-speed computer. ${ }^{15,16)}$

A narrow-band random wave covering 5-25 Hz, which included the main natural modes of the piping system and the equipment system, was used as the input wave for seismic loading. The amplitude of the input acceleration was increased in steps on the basis of observed specimen damage. More details on the experiment conditions may be found in Ref. 17).

\section{Experimental Results}

Examples of the load-displacement curves obtained from the hybrid seismic response experiment are shown in Figs 10 and 11. For the piping support, the dominant damage mode was via accumulated strain at the connections between the mechanical supports around the piping and the frame around the support. The load-displacement relations are shown in Fig. 10 and the photos at the connections after the experiment are shown in Fig. 12. Note that previous studies, which used conventionally analysis, only considered simple forces and their combinations. Therefore, accurate experimental data on the behavior of the joints including the embedded fastener under large-scale random acceleration has not been previously reported. In this experiment for piping supports, we successfully obtained the data and observed some cracks on the surface of the RC structure around the connecting joints. On the other hand, a slipped load-displacement relation was observed at the low load level for the equipment support because of hinges in the joint as shown in Fig. 11.
Table 1 Specimen and experimental cases

\begin{tabular}{|c|c|c|c|c|c|c|}
\hline $\begin{array}{l}\text { Specimen } \\
\text { Type }\end{array}$ & \multicolumn{2}{|c|}{ Structure type } & \multicolumn{2}{|l|}{ Base type } & \multirow{2}{*}{\begin{tabular}{|r} 
Load type \\
Static cyclic \\
\end{tabular}} & \multirow{2}{*}{$\begin{array}{c}\begin{array}{c}\text { Experimenta } \\
\text { Case }\end{array} \\
\text { SS1 } \\
\end{array}$} \\
\hline \multirow{2}{*}{ ss } & \multirow{8}{*}{\begin{tabular}{|l} 
piping \\
support
\end{tabular}} & \multirow{6}{*}{$\begin{array}{l}\text { shape } \\
1\end{array}$} & \multirow{2}{*}{\multicolumn{2}{|c|}{ steel }} & & \\
\hline & & & & & Seismic & SS2 \\
\hline \multirow{4}{*}{ CS1 } & & & \multirow{6}{*}{$\begin{array}{l}\text { RC with } \\
\text { embedded } \\
\text { fastener }\end{array}$} & \multirow{2}{*}{$\begin{array}{l}\text { Fastener } \\
\text { type } 1\end{array}$} & Static cyclic & CS1-1 \\
\hline & & & & & Seismic & CS1-2 \\
\hline & & & & \multirow{2}{*}{$\begin{array}{l}\text { Fastener } \\
\text { type 2 }\end{array}$} & \begin{tabular}{|l} 
Static cyclic \\
\end{tabular} & CS1-3 \\
\hline & & & & & Seismic & CS1-4 \\
\hline CS2 & & \begin{tabular}{|l|} 
shape \\
2
\end{tabular} & & \begin{tabular}{|l|l|}
$\begin{array}{l}\text { Fastener } \\
\text { type } 1\end{array}$ \\
\end{tabular} & Seismic & CS2 \\
\hline $\operatorname{cs} 3$ & & $\begin{array}{l}\text { shape } \\
3 \\
\end{array}$ & & \begin{tabular}{|l}
$\begin{array}{l}\text { Fastener } \\
\text { type } 1\end{array}$ \\
\end{tabular} & Seismic & $\operatorname{cs} 3$ \\
\hline \multirow{2}{*}{$\mathrm{IHX}$} & \multirow{2}{*}{\multicolumn{2}{|c|}{$\begin{array}{l}\text { equipment } \\
\text { support }\end{array}$}} & \multirow{2}{*}{\multicolumn{2}{|c|}{$\begin{array}{l}\mathrm{RC} \text { with embedded } \\
\text { fastener }\end{array}$}} & \begin{tabular}{|l} 
Static cyclic \\
\end{tabular} & $\mathrm{IHX} 1$ \\
\hline & & & & & Seismic & IHX2 \\
\hline
\end{tabular}

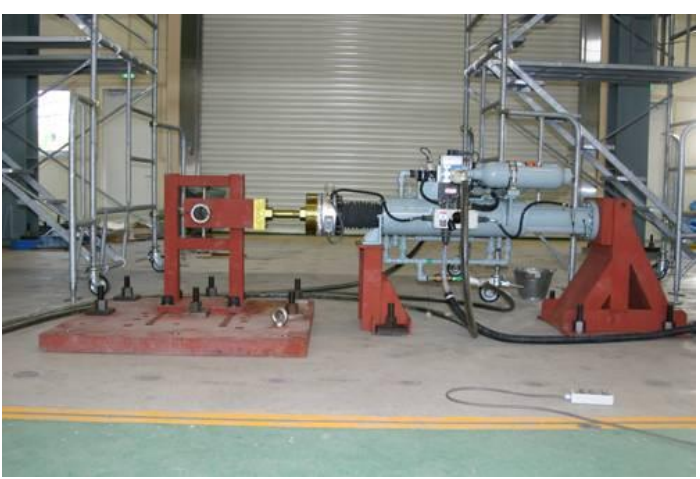

Fig. 7 Hybrid experiment for a piping support

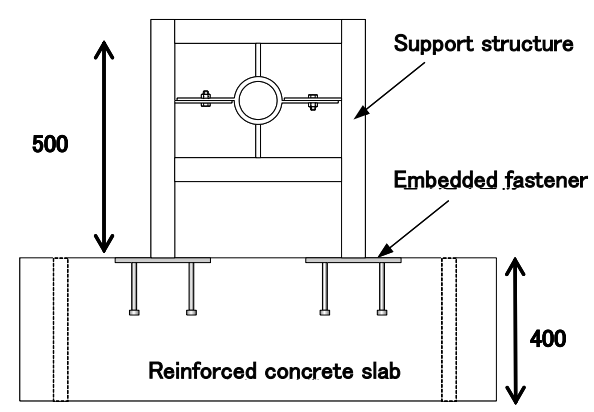

(CS1)

Fig. 8 One kind of piping support experimental specimens

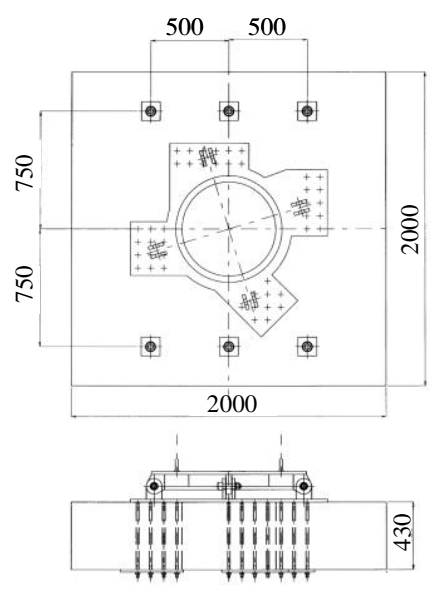

(IHX)

Fig. 9 Equipment support experimental specimen 


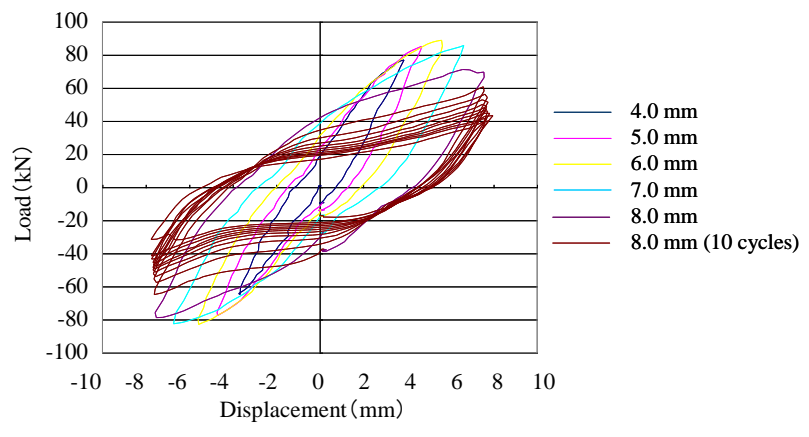

(a) Static cyclic loading test (CS1-1)

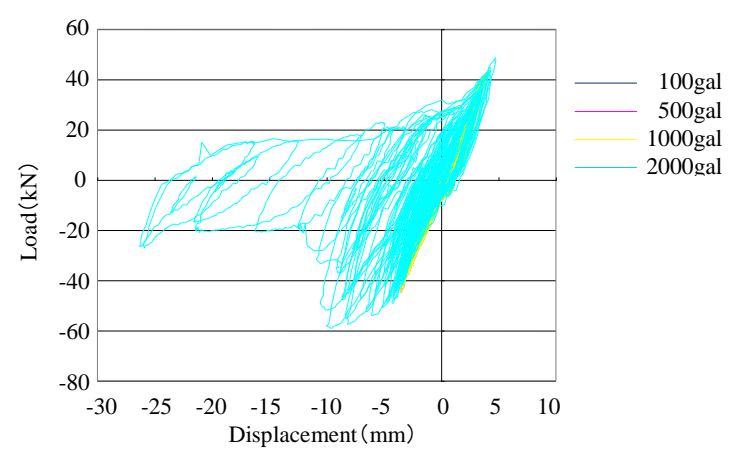

(b) seismic loading test (CS1-2)

Fig. 10 Load-displacement relation for piping support

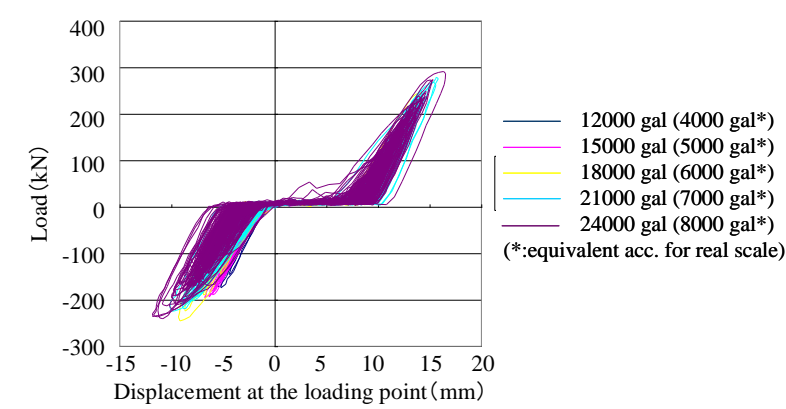

(a) seismic loading test (IHX2, 12000-24000 gal)

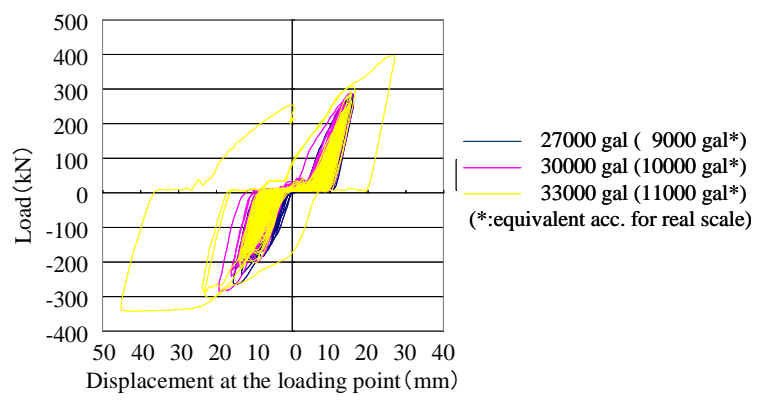

(b) seismic loading test (IHX2, 2700-33000 gal)

Fig. 11 Load-displacement relations for equipment support

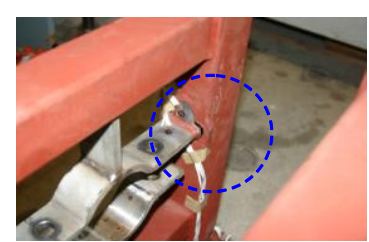

(a) static cyclic loading

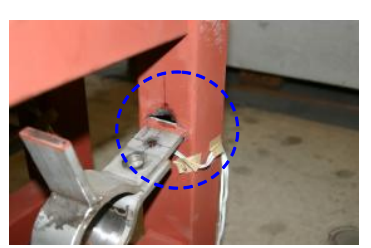

(b) seismic loading
Fig. 12 Examples of experiment results. (a) deformed support pipe and (b) fatigue failure.

\section{Comparison of Proposed Model and Experimental Results}

To validate the proposed model, we substituted the experimental part of the hybrid experiment with a numerical model including the elastic-plastic connection model and compared the predictions with the previously obtained experiment results. The whole system including the piping support is shown in Fig. 13. The whole system including equipment support can be represented by using the structure system of IHX. These whole system were modeled as a one-degree-of-freedom model, as shown in Fig. 14. The each value of the natural frequency of the one-degree-of-freedom model represents the principal natural frequency of the corresponding whole system. Load-displacement relations of piping support and equipment support are shown in Figs. 15 and 16, respectively. It is found that the maximum load and displacement of both analytical results are well suited, whereas the stiffness, which is represented as a gradient of the graph, is a little difference that of the experimental results.

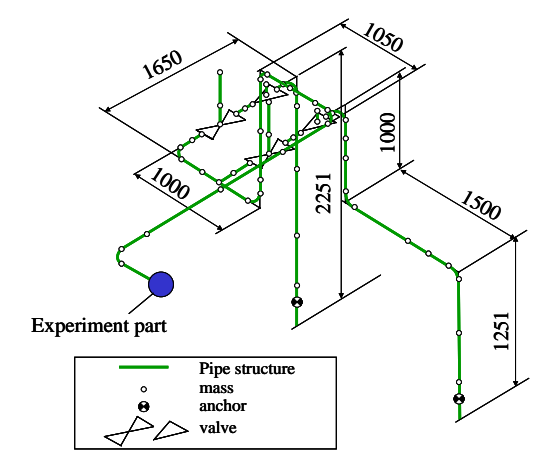

Fig. 13 Whole system including the piping support

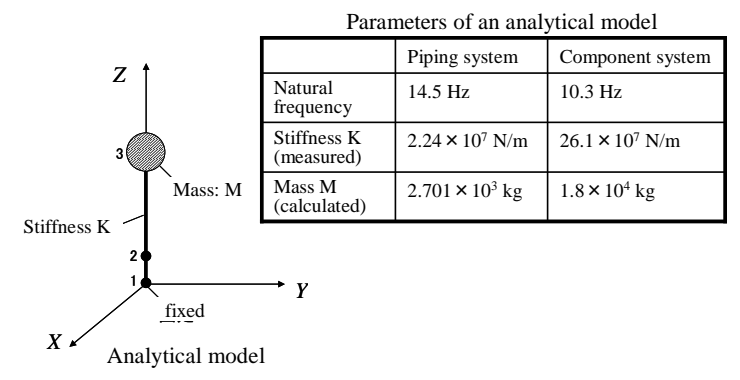

Fig. 14 Analytical model and the parameters

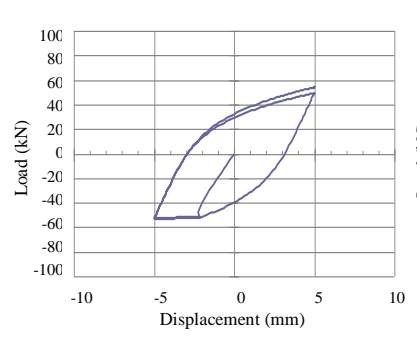

(a) analytical results

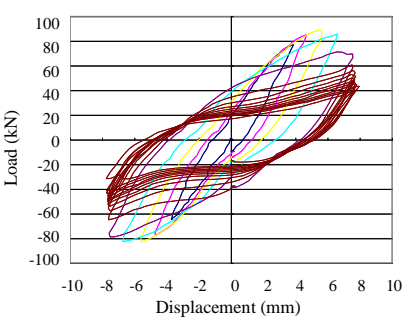

(b) experiment results (see Fig. 10(a) for detail)
Fig. 15 Load-displacement relation (static cyclic loading of piping support) 


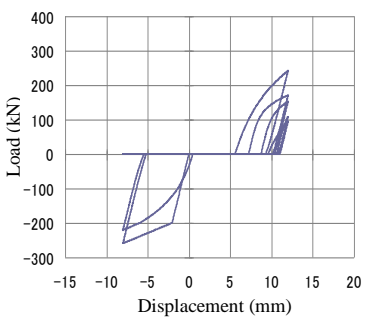

(a) analytical results

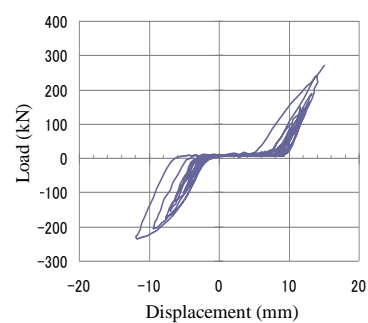

(b) experiment results
Fig. 16 Load-displacement relation (seismic loading of equipment support)

\section{Application to Real-Scale Plant Simulation}

Seismic response analysis was performed for three kinds of real-scale plant systems, listed in Table 2. The primary cooling system, Model 1, is shown in Fig. 17. The joints were modeled by using three dimensional solid elements and springs, and the elastic-plastic connection models were inserted between the support structure and the building. Two cases of seismic response analysis were performed: case 1 using actual seismic observation records at the site, whose maximum accelerations at the base level of the building are $31 \mathrm{~mm} / \mathrm{sec}^{2}$ for horizontal direction and $15 \mathrm{~mm} / \mathrm{sec}^{2}$ for vertical direction, and case 2 using 200-times larger virtual seismic loads. It was confirmed that the predicted basic natural frequency in case 1 was almost equal to the observations in the elastic range (Fig. 18). In case 2, it was confirmed that the hysteresis characteristic of the elastic-plastic connection model could satisfy the given nonlinear rule even if the structure entered the strong nonlinearity area. Examples of the load-displacement relations are shown in Fig. 19. In addition, it was confirmed that the response of the component reduced when the joint was in the elastic-plastic area, and that the basic natural frequency changed. Examples of the time responses at the top of IHX are shown in Fig. 20. By analyzing the frequency characteristics of the time response, it was confirmed that the resonance frequency changed after joint damage shown in Fig. 21. This shows that the elastic-plastic connection model proposed in this research is applicable to a real scale plant simulation.

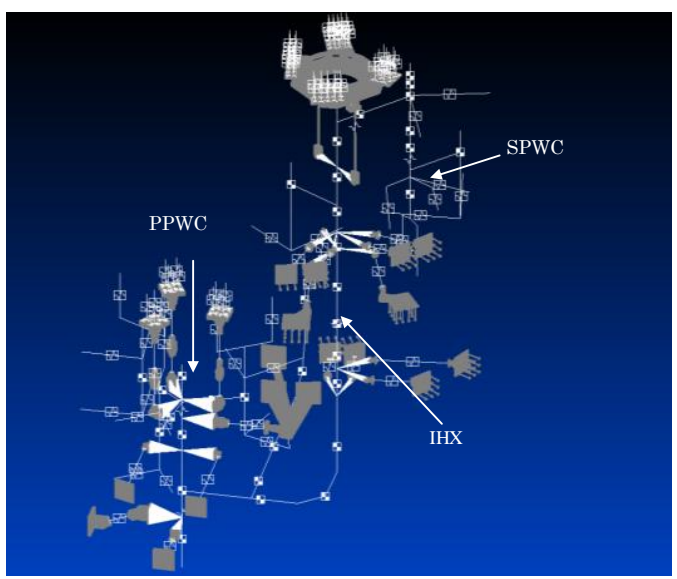

Fig. 17 Analytical model for whole numerical simulation including elastic-plastic connection model

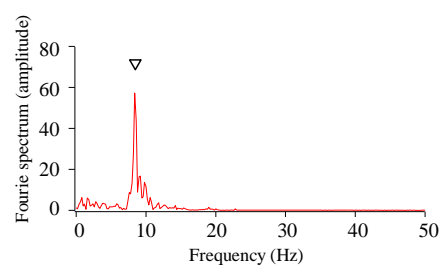

(a) analytical results

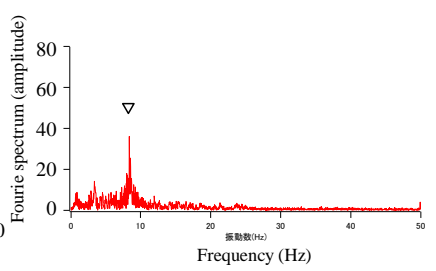

(b) seismic observed results
Fig. 18 Comparison of analytical results and seismic observations (Model 1, top of IHX)

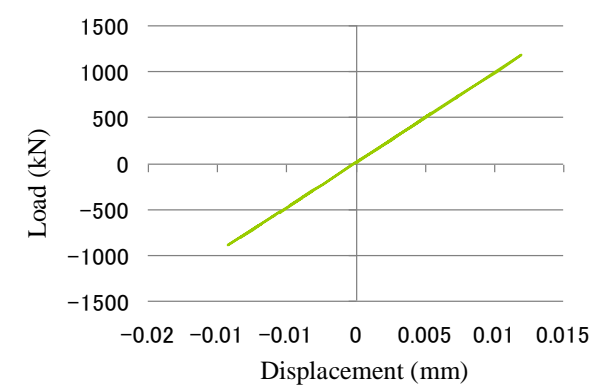

(a) without connection model

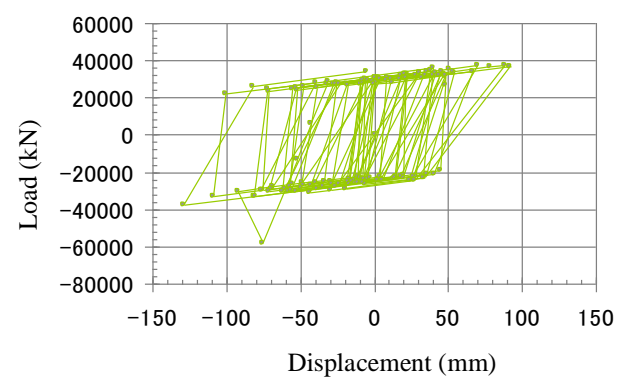

(b) with connection model

Fig. 19 Load-displacement relation at the joint (Model 1, top of IHX)

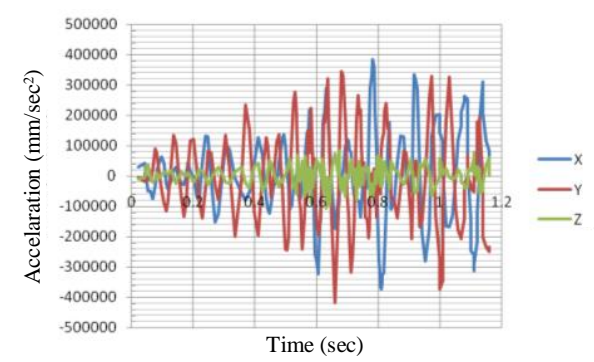

(a) without connection model

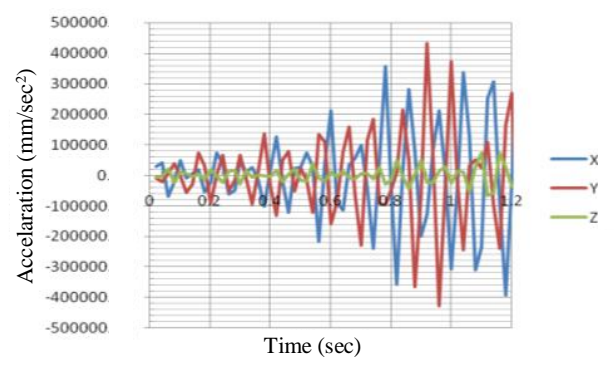

(b) with connection model

Fig. 20 Comparison of time response at the top of IHX (Model 1) 
Table 2 Models for application experiment

\begin{tabular}{ccc}
\hline & Object & Included equipment \\
\hline Model 1 & $\begin{array}{c}\text { Primary cooling } \\
\text { system }\end{array}$ & $\begin{array}{c}\text { Intermediate heat ex- } \\
\text { changer (IHX), primary } \\
\text { pressurized water cooler } \\
\text { (PPWC), secondary pres- } \\
\text { surized water cooler } \\
\text { (SPWC) }\end{array}$ \\
\hline Model 2 & $\begin{array}{c}\text { Reactor pressure } \\
\text { vessel }\end{array}$ & $\begin{array}{c}\text { Reactor pressure vessel } \\
\text { (RPV) }\end{array}$ \\
\hline Model 3 & $\begin{array}{c}\text { Auxiliary cooling } \\
\text { system }\end{array}$ & $\begin{array}{c}\text { Auxiliary heat exchanger } \\
\text { (AHX) }\end{array}$ \\
\hline
\end{tabular}

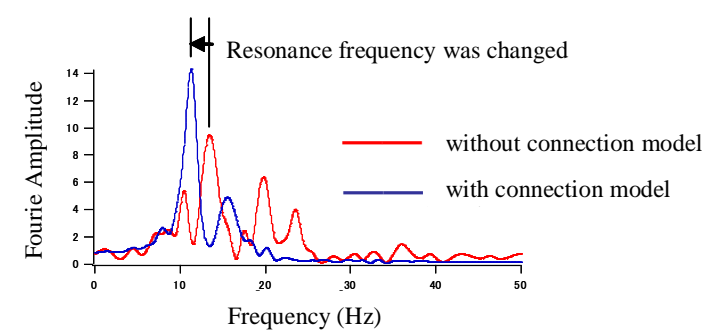

Fig. 21 Comparison of the frequency response at the top of IHX (Model 1, x direction)

\section{Conclusion}

Our conclusions are as follows.

(1) Elastic-plastic connection model

The proposed elastic-plastic connection model for the joints connecting the component supports and the building walls successfully simulates the characteristic hysteresis properties seen in the experimental data, including the effect of the embedded fastener. The model enables structural analysis, permitting the damage of joints, which assumed as a fixed/pinned support in conventional analysis, was established.

(2) Hybrid experiment system

Hybrid experiments afford elastic-plastic hysteresis data and validate the proposed elastic-plastic connection model. In addition, valuable experimental data on the final damage mode for piping supports and equipment supports were obtained.

(3) Real scale plant simulation

A real scale plant simulation could be stably executed with the proposed elastic-plastic connection model, showing the effectiveness of the proposed model.

More detailed analysis will be necessary for complete evaluation of the earthquake-resistance of nuclear plants. Continued work along the present lines may allow detailed analysis of the seismic response of a complete nuclear plant.

\section{Acknowledgment}

The present study is the result of the project entitled "Development of physical model describing the dynamic interaction characteristics of component connections for the analysis of an entire nuclear facility" entrusted to the Japan
Atomic Energy Agency by the Ministry of Education, Culture, Sports, Science and Technology of Japan (MEXT).

\section{References}

1) The White Paper on Nuclear Safety commissioned by the Nuclear Safety Commission of Japan, http://www.nsc.go.jp/NSCenglish/outreach/whitepapers.htm

2) E. Spacone, S. El-Tawil, "Nonlinear analysis of steel-concrete composite structures: state of the art," J. Struct. Eng., 130[2], 159-168 (2004).

3) L. Jason, A. Huerta, G. P. Cabot, S. Ghavamian, "An elastic plastic damage formulation for concrete: Application to elementary tests and comparison with an isotropic damage model," Comput. Meth. Appl. Mech. Eng., 159[52], 7077-7092 (2006).

4) T. Belytschko, K. Mish, "Computability in Nonlinear Solid Mechanics,"(preprint), http://www.tam.northwestern.edu/tb/computability_w_figs.pdf

5) A. Nishida, H. Matsubara, R. Tian, O. Hazama, Y. Suzuki, F. Araya, N. Nakajima, M, Tani, M. Kondo, "Numerical simulation system "three-dimensional virtual plant vibration simulator" for nuclear plants by using assembled structural analysis," Trans. At. Energy Soc. Japan, 6[3], 376-382 (2007), [in Japanese].

6) Design Recommendations for Composite Constructions, Architectural Institute of Japan (1985), [in Japansese].

7) Y. Chen, K. Ohi, K. Takanashi, "The inelastic behavior of square-box steel beam-columns subject to tri-directional varying loads," J. Struct. Constr. Eng., 447, 139-148 (1993), [in Japanese].

8) Y. Chen, K. Ohi, K. Takanashi, "A Simplified model of steel structural members with strength deterioration used for earthquake response analysis," J. Struct. Constr. Eng., 437, 115-124 (1992), [in Japanese].

9) P. S. Jennings, "Periodic response of a general yielding structure," $J$. Eng. Mech. Div., 90[EM2], 131-165 (1964).

10) A. Yano, S. Sugaie, Y. Matsuzaki, Y Abe, S. Usami et al., "An experimental study about support structures for piping and components including embedded fasteners," part 1-12, Summaries of technical papers of Annual Meeting AIJ, (1979-1982), [in Japanese].

11) T. Okada, K. Takanashi, M. Seki, H. Taniguchi et al., "Strength and failure mechanism of equipment anchorage with studs," part 1-4, Summaries of technical papers of Annual Meeting AIJ, (1979, 1982, 1983), [in Japanese].

12) T. Miyashita, H. Shimizu, H. Morikawa, Y. Hayami, "Numerical analysis of a pulling experiment of studs by using FEM," Summaries of technical papers of Annual Meeting AIJ, 1809-1810 (1980), [in Japanese].

13) Y. Abe, S. Usami, Y. Matsuzaki, "The influence of anchor hook shape and head size on the tensile strength of pre-set anchor," Summaries of technical papers of Annual Meeting AIJ, 1905-1906 (1983), [in Japanese].

14) S. Usami, Y. Abe, Y. Matsuzaki, "Study on the fatigue behavior of anchor for supporting equipment and piping : tensile fatigue strength against cone-shaped concrete failure," Summaries of technical papers of Annual Meeting AIJ, 1907-1908 (1983), [in Japanese].

15) T. Horiuchi, T. Konno, "Development of Real-Time Hybrid experimental System with Actuator Delay Compensation (5th Report, Improvement of Methods for Compensating Actuaor Delay)," Trans. Jpn. Soc. Mech. Eng., C67[655], 77-85 (2001), [in Japanese].

16) K. Saizuka, Y. Itoh, E. Kiso, T. Usami, "A consideration on procedures of hybrid earthquake response test taking account of the scale factor," J. Struct. Mech. Earthquake Eng., 507, 179-190 (1995), [in Japanese].

17) The result of "Development of physical model describing the dynamic interaction characteristics of component connections for the analysis of an entire nuclear facility," MEXT (2009), [in Japanese]. 